\title{
FATORES DIFICULTADORES À PERMANÊNCIA DOS ALUNOS NO CURSO DE GRADUAÇÃO EM ADMINISTRAÇÃO A DISTÂNCIA DA UNIVERSIDADE FEDERAL DE SANTA CATARINA
}

\author{
Andressa Sasaki Vasques Pacheco - Universidade Federal de Santa Catarina - \\ andressa@ead.ufsc.br \\ Marina Keiko Nakayama - Universidade Federal de Santa Catarina - \\ marina@egc.ufsc.br \\ Fernando José Spanhol - Universidade Federal de Santa Catarina - \\ spanhol@led.ufsc.br \\ Pedro Antônio de Melo - Universidade Federal de Santa Catarina - \\ pedromelo@inpeau.ufsc.br \\ Maurício Rissi - Universidade Federal de Santa Catarina - \\ mauriciorissi@ead.ufsc.br \\ Kelly Cristina Benetti - Universidade Federal de Santa Catarina - \\ kellyadm@ hotmail.com \\ Aline Pereira Soares - Universidade Federal de Santa Catarina - \\ alinepsoares@yahoo.com.br
}

\section{RESUMO}

A educação é uma das principais bases para o crescimento econômico e social de um país. Para isso, o Governo brasileiro vem incentivando ações para o desenvolvimento da Educação a Distância nas IES, tendo como um dos pontos principais dessa ação da UAB/MEC o projeto piloto do curso de Administração a distância. Em busca de informações para uma das IES participante desse projeto, este trabalho objetivou analisar os fatores dificultadores à permanência dos alunos no curso de graduação em Administração a distância da Universidade Federal de Santa Catarina. Quanto aos procedimentos metodológicos caracteriza-se como: teórico-empírico, descritivo, expost-facto, aplicado, bibliográfica, participante e estudo de caso, com abordagem predominantemente quantitativa. Os principais fatores dificultadores aos estudantes foram: tempo para estudar, carga horária semanal de trabalho, adaptação à modalidade a distância, situação econômica financeira e responsabilidade econômica no sustento da família, contato com o professor, a ausência de tutores nos pólos, acesso a bibliotecas, reprovação em mais de duas disciplinas no semestre, contato com os colegas do curso, prazo de entregas das atividades e grau de dificuldade dos exercícios e provas. Por fim, recomenda-se o monitoramento contínuo dos fatores dificultadores aos alunos, podendo assim criar prognósticos consistentes para prevenção da evasão.

Palavras-chaves: Evasão. Educação a distância. Dificuldades estudantes.

FACTORS THAT DIFFICULT THE PERMANENCE OF THE STUDENTS IN THE GRADUATION COURSE OF ADMINISTRATION OF THE UNIVERSIDADE FEDERAL DE SANTA CATARINA BY DISTANCE.

\section{ABSTRACT}

Education is one of the main bases for the economic and social growth of a country. The superior education expansion at Brazil, because of its territorial extension, is a challenge for the governing. In a search of information for one of the participant institutions of 
this project, this work objectified to analyze the factors that difficult the permanence of the students in the graduation course of Administration of the Universidade Federal de Santa Catarina by distance. About the methodological procedures it is characterized as: theoretician-empiricist, description, ex-post-facto, applied, bibliographical, participant and case study, with predominantly quantitative boarding. The main dificult factors for the students had been: time to study, weekly time load of work, adaptation to distance education, financial economic situation and economic responsibility in the family sustenance, contact with the professor, the absence of tutors in their polar regions, access to the libraries, reprovation in more than two disciplines in same semester, contact with the course colleagues, stated period of deliveries of the activities and exercises and tests degree of difficulty. Finally, it is recommended the continuous monitoring factors that difficult for the students, being able to create consistent prognostics on the reality of this phenomenon.

Key-words: Evasion. Distance education. Difficult for the students.

\section{INTRODUÇÃO}

Os recentes e constantes avanços das tecnologias de informação e comunicação relativizaram os conceitos de espaço geográfico e tempo, reduzindo virtualmente as distâncias territoriais e otimizando o tempo gasto para acessar o vasto acervo da produção cultural da humanidade que ora é disponibilizado na rede internacional de computadores (ABRAEAD, 2007).

Neste contexto, a modalidade de educação a distância foi potencializada, culminando em uma educação cada vez mais próxima e personalizada, além de privilegiar a troca de conhecimentos em rede e, com isso, instigar o surgimento de comunidades de aprendizagem (ABRAEAD, 2007).

Diante do crescimento dessa modalidade e de um futuro otimista para a $\mathrm{EaD}$, percebe-se que nem todas as instituições estão conseguindo obter resultados favoráveis, visto que o planejamento de cursos com tais características não é tão parecido com o do meio presencial. O desafio é usar a educação à distância de forma mais sistemática, integrada à estrutura educacional da região, de modo a melhorar a qualidade, a eficácia e a eficiência da educação e do treinamento, provendo oportunidades educacionais mais amplas e variadas (UNESCO, 1997).

Um dos problemas enfrentados pelos gestores das IES é a evasão nessas instituições. Corroborando com essa afirmação, Biazus (2004) destaca que é importante verificar e levantar as razões (causas) contribuintes à evasão e as dificuldades dos alunos, com o intuito de minimizar o número dos acadêmicos que abandonam o ensino superior.

Na ampliação do ensino superior no Brasil, tem-se o projeto piloto de um curso de graduação em Administração a distância. Este projeto está presente em mais de 20 estados brasileiros e é resultado de uma parceria entre a UAB - Universidade Aberta do Brasil (projeto pertencente ao Ministério da Educação - MEC) e Banco do Brasil.

Com o intuito de favorecer a gestão deste curso, com um controle a possíveis evasões, procurou delimitar: "Quais são os fatores dificultadores a permanência dos alunos no curso de graduação em Administração a distância da Universidade Federal de Santa Catarina?" 


\section{FUNDAMENTAÇÃO TEÓRICA}

\subsection{EDUCAÇÃO A DISTÂNCIA - EAD}

De acordo com Barberá (2006) até recentemente, a educação a distância nacional não apresentava credibilidade por parte de sociedade brasileira, tendo assim que reverter este quadro, já que é um mercado crescente.

Russel (apud BARBERÀ, 2006) corrobora com essa afirmação ao salientar que não há uma diferença significativa entre a aprendizagem a distância e a aprendizagem tradicional em uma sala de aula. Em outras palavras, a aprendizagem a distância pode ser considerada tão efetiva como a aprendizagem presencial.

Muitas são as definições possíveis e apresentadas, mas há um consenso mínimo em torno da idéia de que EaD é a modalidade de educação em que as atividades de ensino-aprendizagem são desenvolvidas majoritariamente (e em bom número de casos exclusivamente) sem que alunos e professores estejam presentes simultaneamente no mesmo lugar (ABRAEAD, 2006).

Destaca-se o conceito de EaD norteador dessa pesquisa, que define que a educação a distância se define como: educação formal, baseada em uma instituição na qual o grupo de aprendizagem se separa e na qual se utilizam sistemas de telecomunicações interativos para conectar estudantes, recursos e instrutores (SIMONSON, 2006).

Quanto as diferenças entre o ensino presencial e o a distância, Aretio (2002) apresenta em sua obra comparativos entre essas modalidades, quanto ao papel do estudante, do professor, das tecnologias e da gestão.

Para o estudante, a aprendizagem aberta e a distancia significa maior facilidade de acesso e com isto uma gama mais ampla de oportunidades para estudar e se qualificar. Percebe-se que uma das características mais importantes nos estudantes de EaD é sua idade, sendo a população adulta, o principal público alvo dessa modalidade. Quanto ao estudo na idade adulta, Aretio (2002) afirma que está demonstrado que a capacidade do adulto para aprender continua vigente, não ficou minguada em sua juventude. Convém, no entanto, identificar quais são as dificuldades, os problemas e os obstáculos, mais significativos para este aprender, que nascem de sua idade, de seu status e, evidentemente, de suas próprias características biopsicosociológicas.

Continuando a exposição das características da $\mathrm{EaD}$, o professor tem como função principal elaborar as metodologias utilizadas na sua disciplina, de forma que esta contempla a criação, o armazenamento, a disseminação e o controle do conhecimento. O tutor é o responsável pelo acompanhamento dos estudantes, sendo o elo entre o aluno e o professor.

O terceiro ponto a ser analisado é a comunicação e os recursos em EaD. Como já explicitado no histórico dessa modalidade, a evolução das mídias eletrônicas pode ser considerada uma das maiores responsáveis pela maximização do uso de sistemas a distância. Desta forma, o atendimento ao aluno tornou-se possível em qualquer localidade do mundo, desde que este tenha como acessar a tecnologia e, principalmente, em "tempo real", fazendo com que a utilização da EaD em programas educacionais venha aumentando consideravelmente com o passar dos anos.

Quanto a gestão da EaD, a UNESCO (1997) destaca que é necessária uma equipe com dedicação integral ou que preste consultoria externa, para planejar, elaborar instruções, desenvolver e produzir programas, realizar pesquisar, prestar assessoria como especialistas de mídia, marketing ou para integrar a equipe administrativa.

Em complemento, destaca-se que para que se concretize um curso a distância é necessária a implementação de uma infra-estrutura adequada, profissionais capacitados 
para a realização das atividades de planejamento, elaboração de materiais, avaliação e serviços de apoio aos alunos e professores (MORAES, 2004).

\subsection{FATORES DIFICULTADORES E EVASÃO NA EDUCAÇÃO A DISTÂNCIA}

Na modalidade a distância, conforme Rumble (2003), em geral, as taxas de conclusão são bastantes fracas e os índices de evasão altos, mas a comparação entre os índices das IES é prejudicado pelos diferentes cálculos aplicados.

De acordo com Rumble (2003), a evasão é encarada como um fracasso para as IES, mas salienta que alguns estudantes decidem freqüentar um curso sem a preocupação de cumprir todos os requisitos ou de passar nos exame, fazendo com que se considerar somente índices de conclusão e abandono não sejam uma boa medida para avaliar o sucesso individual dos estudantes.

Essa afirmação é rebatida pela UNESCO (1997), ao se tratar dos custos da IES, ao afirmar que um elemento muito relevante na comparação de custos é o índice de formandos ou taxa de estudantes que completam os estudos. Resgata-se essa discussão por considerar a evasão não somente como um problema de custo de uma IES, mas também como um problema social.

Quanto aos fatores atribuíveis à instituição podem-se destacar algumas características como: o material didático não é o apropriado; as Unidades Didáticas, os textos recomendados, o áudio, o vídeo e a hipermídia não são adequados para a metodologia de estudo; não há suficiente coerência entre objetivos, conteúdos, atividades; a carga acadêmica é excessiva ou o nível é inadequado; os autores dos materiais e as equipes docentes não planejam corretamente as atividades para desenvolver o aluno e para a aprendizagem buscada; o acesso aos meios tecnológicos é deficiente; deficiências no suporte de tutorias; poucas sessões de tutoria (presenciais ou a distância) e difícil comunicação com os professores e tutores.

Já as circunstâncias sócio-familiares dos alunos de acordo com Aretio (2002) são: as ocupações laborais exigem muita dedicação física e mental; a dificuldade de ânimo para realizar atividades de estudo; a responsabilidade familiar; a atenção à família; os problemas familiares; entorno pouco favorável; falta de apoio do entorno laboral e, sobretudo, familiar.

Como exemplo dos fatores psicopedagógicos tem-se: o não conhecimento da instituição, de sua metodologia e de seu nível de exigência; acessos ao centro de estudos sem a preocupação de que a aprendizagem supõe um esforço que, a distância, é superior; falta de técnicas e hábitos de estudo; não se está habituado a utilizar as novas tecnologias que agora são uma ferramenta importante para a obtenção de informação e as interações formativas a distância; falta de estímulo e motivação; desalento pelo recebimento de qualificações baixas de uma avaliação e medo de apresentar-se nas provas presenciais.

Aretio (2002) complementa ainda que essa é uma seleção de causas de abandono ou de baixo rendimento. Mas as pesquisas estabeleceram uma ordem de prioridade entre os diferentes fatores conforme se segue: atenção às obrigações laborais; atenção à família; falta de dedicação ao estudo; falta de motivação; equivocada imagem que se tem sobre a instituição e seu nível de exigência; dificuldade de superar as provas presenciais; falta de hábitos, técnicas de estudo e adaptação às tecnologias; falta de preparação prévia; e materiais didáticos deficientes.

Outros fatores analisados por Maia e Meirelles (2005), são os Ambientes Virtuais de Ensino e Aprendizagem (AVEA) e a forma de desenho do curso. O desenho do curso relaciona-se à forma como o curso está estruturado considerando a tecnologia computacional, sendo as principais: a videoconferência, a teleconferência, a internet e o 
CD-ROM. Dessa maneira, destacam que o índice de evasão mantém relação com a tecnologia utilizada no curso a distância.

Ao empreender estudo afim, Biazus (2004) identificou um conjunto de fatores determinantes para o processo de evasão, apresentando-se assim uma sistemática de avaliação do processo de ensino-aprendizagem para o ensino superior presencial com ênfase em Cursos de Ciências Contábeis. Esse modelo divide os fatores em externos e internos às IES.

A categoria interna é formada por três componentes: atitude comportamental; motivos institucionais e requisitos didático-pedagógicos.

Ainda de acordo com Biazus (2004) apresenta-se a seguir a dimensão externa, formada por quatro componentes, que identificam dezoito (18) indicadores considerados relevantes para o estudo do modelo proposto pelo pesquisador, e conforme os estudos existentes sobre as causas da evasão. Os quatro componentes externos identificados são: vocação pessoal; características individuais; conjunturais e sócio-político-econômicas, cujas categorias tem por finalidade detectar problemas de ordem pessoal, vocacional, mercado de trabalho, financeira, dificuldades ambientais e sócio-culturais.

Neste caso, a instituição (curso) deve estar acompanhando e tomando providências, continuamente, no sentido de interagir com as oportunidades e ameaças ambientais, levando em consideração sempre atividades da instituição e nunca esquecendo sua missão e seus objetivos, porque o papel da universidade também é de garantir a qualidade do curso, como a de sua conclusão por parte do aluno (BIAZUS, 2004).

\section{PROCEDIMENTOS METODOLÓGICOS}

Quanto ao tipo de estudo, caracteriza-se como teórico-empírico, descritivo, expost-facto, aplicado, bibliográfica e estudo de caso. Em relação à abordagem desta pesquisa, classifica-se como predominante quantitativa.

Os principais dados secundários coletados dizem respeito a fatores de evasão no ensino superior, características de cursos a distância, índices de evasão em diversos cursos. Esses dados balizaram a formulação do instrumento de coleta de dados junto ao público alvo.

Em relação aos fatores dificultadores aos alunos, a população alvo foram os alunos freqüentes ao curso, sendo a população acessível aos alunos que comparecem a primeira chamada da prova presencial de Processo Decisório do curso de Administração a distância da UFSC, alcançando-se um número de 259 respondentes.

Quanto ao questionário para a avaliação dos fatores dificultadores aos alunos, utilizou-se a seguinte escala verbal: não dificulta, dificulta pouco, dificulta e dificulta muito.

Para a análise dos fatores, utilizou-se a divisão por categorias de análise propostas por Biazus (2004), sendo que tem-se duas dimensões de análise, as categorias internas às IES e as externas às IES.

\section{RESULTADOS DA PESQUISA}

A UFSC é uma das instituições que aderiram a modalidade a distância. Com o incentivo de um projeto da Universidade Aberta, a UFSC tem ampliado o contingente de estudantes atingidos por meio do ensino a distância.

Nesse contexto e em resposta à demanda motivada pelo Ministério de Educação, com a finalidade de atender às necessidades das empresas estatais em termos de qualificação dos seus servidores públicos, a Universidade Federal de Santa Catarina - 


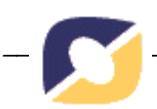

UFSC, juntamente com outras instituições de ensino superior, participou do projeto de criação do Curso de Graduação em Administração, na modalidade a distância, como um programa da Universidade Aberta do Brasil - UAB/MEC.

O curso conta com dez pólos de ensino em todo o Estado de Santa Catarina: Araranguá, Criciúma, Laguna, Palhoça, Florianópolis, Tubarão, Joinville, Canoinhas, Lages e Chapecó. Nesses municípios, a UFSC disponibiliza aos estudantes pólos de estudo com infra-estrutura técnica e pedagógica (coordenador de pólo e monitor) que são utilizados para as atividades presenciais e como base de apoio para os estudos, durante todo o curso.

Iniciando-se a análise dos fatores dificultadores a aprendizagem dos alunos a distância, resgata-se as informações apresentadas na metodologia. Realizou-se essa análise por meio da aplicação de um questionário com os alunos freqüentes ao curso, com o intuito de verificar suas dificuldades, para que se possa posteriormente analisar essas informações com os fatores contribuintes à evasão, gerando assim um diagnóstico sobre a situação do curso.

Apresenta-se a seguir os resultados quanto às categorias externas às IES. Tabela 01: Categoria Sócio-político-econômica - fatores dificultadores

\begin{tabular}{|c|c|c|c|c|c|c|c|c|c|c|}
\hline & \multicolumn{2}{|c|}{ Não dificulta } & \multicolumn{4}{|c|}{$\begin{array}{l}\text { Dificulta } \\
\text { pouco }\end{array}$} & \multicolumn{2}{|c|}{ Dificulta muito } & \multicolumn{2}{|l|}{ Total } \\
\hline & Freq & & Freq & & & & & & Freq & \\
\hline & Abs. & $\begin{array}{l}\text { Freq. } \\
\text { Rel. }\end{array}$ & Abs. & $\begin{array}{l}\text { Freq. } \\
\text { Rel. }\end{array}$ & $\begin{array}{l}\text { Freq. } \\
\text { Abs. }\end{array}$ & $\begin{array}{l}\text { Freq. } \\
\text { Rel. }\end{array}$ & $\begin{array}{l}\text { Freq. } \\
\text { Abs. }\end{array}$ & $\begin{array}{l}\text { Freq. } \\
\text { Rel. }\end{array}$ & Abs. & $\begin{array}{l}\text { Freq. } \\
\text { Rel. }\end{array}$ \\
\hline $\begin{array}{l}\text { Apoio da empresa que } \\
\text { trabalha para fazer este curso }\end{array}$ & 203 & $63,84 \%$ & 73 & $22,96 \%$ & 26 & $\begin{array}{l}8,18 \% \\
17,54\end{array}$ & 16 & $5,03 \%$ & 318 & $100,00 \%$ \\
\hline Tempo para estudar & 94 & $28,92 \%$ & 124 & $38,15 \%$ & 57 & $\%$ & 50 & $15,38 \%$ & 325 & $100,00 \%$ \\
\hline $\begin{array}{l}\text { Carga horária Semanal de } \\
\text { trabalho }\end{array}$ & 150 & $46,58 \%$ & 124 & $38,51 \%$ & 31 & $9,63 \%$ & 17 & $5,28 \%$ & 322 & $100,00 \%$ \\
\hline $\begin{array}{l}\text { Deslocamento ao pólo de } \\
\text { ensino }\end{array}$ & 206 & $63,98 \%$ & 62 & $19,25 \%$ & 36 & $\begin{array}{l}11,18 \\
\%\end{array}$ & 18 & $5,59 \%$ & 322 & $100,00 \%$ \\
\hline $\begin{array}{l}\text { Acesso a computador e ou } \\
\text { internet para estudo }\end{array}$ & 259 & $79,94 \%$ & 45 & $13,89 \%$ & 13 & $4,01 \%$ & 7 & $2,16 \%$ & 324 & $100,00 \%$ \\
\hline Compreensão das matérias & 161 & $50,16 \%$ & 135 & $42,06 \%$ & 19 & $5,92 \%$ & 6 & $1,87 \%$ & 321 & $100,00 \%$ \\
\hline $\begin{array}{l}\text { Adequaçao do conteudo com } \\
\text { o trabalho }\end{array}$ & 157 & $48,91 \%$ & 117 & $36,45 \%$ & 33 & $\%$ & 14 & $4,36 \%$ & 321 & $100,00 \%$ \\
\hline
\end{tabular}

Fonte: dados primários

Quanto às dificuldades citadas pelos estudantes quanto à categoria sóciopolítico-econômica, pode-se observar que "tempo para estudar" foi o indicador mais citado com $71,08 \%$ de respostas, sendo $15,38 \%$ na escala dificulta muito. Outro fator correlacionado é a carga horária semanal de trabalho, na qual 53,42\% dos estudantes apresentaram-na como fator que dificulta os estudos.

Já em relação à compreensão das matérias, 49,84\% disseram ter alguma dificuldade, ainda que este não seja um fator preponderante. A adequação do conteúdo com o trabalho também apresentou índices próximos a 50\%, com 36,45\% dos respondentes afirmando que este item dificulta um pouco seus estudos e aprendizagem.

A segunda categoria externa à IES analisada foi a vocação pessoal. Analisando os dados desta, constata-se que nenhum indicador apresentou percentual relevante quanto à dificuldade de estudos, sendo que o maior índice foi o de estar cursando paralelamente outro curso, com $26,90 \%$ das respostas.

Outro fator a ser destacado foi o desconhecimento prévio a respeito do curso de Administração a distância, com 26,43\%, o que pode indicar uma má divulgação do curso durante seu processo seletivo, que pode ter levado a uma imagem errônea do mesmo. 
Quanto aos indicadores da categoria características individuais, destaca-se o item adaptação à modalidade a distância, com 39,63\% dos alunos apresentando-se como fator que atrapalha seus estudos.

Os outros indicadores desta categoria, como problemas de saúde e atendimento do curso às expectativas prévias tiveram resultados semelhantes, com cerca de $30 \%$ dos entrevistados, apresentando-se como fatores que dificultam seu estudo e aprendizado.

Tabela 02: Categoria Conjuntural - fatores dificultadores

\begin{tabular}{|c|c|c|c|c|c|c|c|c|c|c|}
\hline & \multicolumn{2}{|c|}{ Não dificulta } & \multicolumn{2}{|c|}{ Dificulta pouco } & \multicolumn{2}{|c|}{ Dificulta } & \multicolumn{2}{|c|}{ Dificulta muito } & \multicolumn{2}{|l|}{ Total } \\
\hline & $\begin{array}{l}\text { Freq. } \\
\text { Abs. }\end{array}$ & $\begin{array}{l}\text { Freq. } \\
\text { Rel. }\end{array}$ & $\begin{array}{l}\text { Freq. } \\
\text { Abs. }\end{array}$ & $\begin{array}{l}\text { Freq. } \\
\text { Rel. }\end{array}$ & $\begin{array}{l}\text { Freq. } \\
\text { Abs. }\end{array}$ & $\begin{array}{l}\text { Freq. } \\
\text { Rel. } \\
\end{array}$ & $\begin{array}{l}\text { Freq. } \\
\text { Abs. }\end{array}$ & $\begin{array}{l}\text { Freq. } \\
\text { Rel. }\end{array}$ & $\begin{array}{l}\text { Freq. } \\
\text { Abs. }\end{array}$ & $\begin{array}{l}\text { Freq. } \\
\text { Rel. } \\
\end{array}$ \\
\hline Situação econômica financeira & 209 & $65,93 \%$ & 71 & $22,40 \%$ & 27 & $8,52 \%$ & 10 & $3,15 \%$ & 317 & $100,00 \%$ \\
\hline Influência familiar & 237 & $73,83 \%$ & 56 & $17,45 \%$ & 17 & $5,30 \%$ & 11 & $3,43 \%$ & 321 & $100,00 \%$ \\
\hline Mudança de residência ou cidade & 241 & $80,87 \%$ & 38 & $12,75 \%$ & 8 & $2,68 \%$ & 11 & $3,69 \%$ & 298 & $100,00 \%$ \\
\hline $\begin{array}{l}\text { Mudança de estado civil } \\
\text { Responsabilidade econômica no sustento da }\end{array}$ & 256 & $88,28 \%$ & 17 & $5,86 \%$ & 9 & $3,10 \%$ & 8 & $2,76 \%$ & 290 & $100,00 \%$ \\
\hline família & 202 & $64,95 \%$ & 73 & $23,47 \%$ & 27 & $8,68 \%$ & 9 & $2,89 \%$ & 311 & $100,00 \%$ \\
\hline
\end{tabular}

Fonte: dados primários

Apresentando a última categoria externa à IES, tem-se finalmente a categoria conjuntural, na qual se pôde destacar dois indicadores correlacionados, a situação econômica financeira e a responsabilidade econômica no sustento da família. Estes apresentam cerca de $35 \%$ das respostas indicando dificuldades dos estudantes.

Iniciando-se a análise das categorias internas as IES, tem-se a atitude comportamental. Como destaque nessa categoria, apresentam-se os índices do contato com o professor, visto pela maioria dos alunos $(56,29 \%)$ como limitador ao seu estudo e aprendizagem. Mesmo esta sendo uma característica da $\mathrm{EaD}$, podem-se projetar algumas ações para amenizar essa falta de contato, como encontros presenciais, a visita de professores aos pólos, chats e videoconferências. O curso em estudo realiza algumas dessas ações, mas pode intensificar esse contato, visto o percentual de alunos que indicou esse fator.

Outro fator relacionado com os docentes é a didática dos professores, apontada por 32,30\% dos entrevistados. Uma ação que pode melhorar este item é a intensificação de capacitação de docentes para o trabalho na modalidade a distância, pois muitos apresentam dificuldades principalmente com o uso de novas tecnologias, como videoconferências, e outras ferramentas dos AVEAs.

Quanto aos indicadores relativos à tutoria, motivação e incentivo por parte do tutor e relacionamento com este, destaca-se que a maioria indicou que esses fatores não dificultam ou dificultam pouco os estudos e aprendizagem. Ressalta-se que a tutoria é um dos elementos chaves de um curso de $\mathrm{EaD}$, e com esses resultados indica-se um trabalho satisfatório desses agentes do processo de ensino-aprendizagem.

Tabela 03: Categoria Motivos Institucionais - fatores dificultadores

\begin{tabular}{|c|c|c|c|c|c|c|c|c|c|c|}
\hline & \multicolumn{2}{|c|}{ Não dificulta } & \multicolumn{2}{|c|}{ Dificulta pouco } & \multicolumn{2}{|c|}{ Dificulta } & \multicolumn{2}{|c|}{ Dificulta muito } & \multicolumn{2}{|l|}{ Total } \\
\hline & $\begin{array}{l}\text { Freq. } \\
\text { Abs. }\end{array}$ & $\begin{array}{l}\text { Freq. } \\
\text { Rel. }\end{array}$ & $\begin{array}{l}\text { Freq. } \\
\text { Abs. }\end{array}$ & $\begin{array}{l}\text { Freq. } \\
\text { Rel. }\end{array}$ & $\begin{array}{l}\text { Freq. } \\
\text { Abs. }\end{array}$ & $\begin{array}{l}\text { Freq. } \\
\text { Rel. }\end{array}$ & $\begin{array}{l}\text { Freq. } \\
\text { Abs. }\end{array}$ & $\begin{array}{l}\text { Freq. } \\
\text { Rel. }\end{array}$ & $\begin{array}{l}\text { Freq. } \\
\text { Abs. }\end{array}$ & $\begin{array}{l}\text { Freq. } \\
\text { Rel. }\end{array}$ \\
\hline Ausência de tutores nos pólos & 162 & $51,10 \%$ & 98 & $30,91 \%$ & 32 & $10,09 \%$ & 25 & $7,89 \%$ & 317 & $100,00 \%$ \\
\hline Acesso a bibliotecas & 177 & $55,66 \%$ & 94 & $29,56 \%$ & 30 & $9,43 \%$ & 17 & $5,35 \%$ & 318 & $100,00 \%$ \\
\hline Estrutura dos pólos de ensino & 220 & $70,29 \%$ & 60 & $19,17 \%$ & 19 & $6,07 \%$ & 14 & $4,47 \%$ & 313 & $100,00 \%$ \\
\hline $\begin{array}{l}\text { Laboratório de informática nos pólos de } \\
\text { ensino }\end{array}$ & 211 & $74,04 \%$ & 43 & $15,09 \%$ & 17 & $5,96 \%$ & 14 & $4,91 \%$ & 285 & $100,00 \%$ \\
\hline aprendizagem & 244 & $76,49 \%$ & 64 & $20,06 \%$ & 6 & $1,88 \%$ & 5 & $1,57 \%$ & 319 & $100,00 \%$ \\
\hline $\begin{array}{l}\text { Meios de comunicação oferecidos para } \\
\text { contato }\end{array}$ & 261 & $81,31 \%$ & 50 & $15,58 \%$ & 9 & $2,80 \%$ & 1 & $0,31 \%$ & 321 & $100,00 \%$ \\
\hline
\end{tabular}

Fonte: dados primários 
Os motivos institucionais, próxima categoria a ser analisada, tiveram alguns destaques em seu resultado. Primeiramente a ausência de tutores nos pólos, citada por 48,90\% dos entrevistados. Mesmo representando um percentual expressivo, deve-se enfatizar que se tem feito constantes avaliações do desempenho da tutoria, obtendo-se resultados favoráveis, como os observados na categoria atitude comportamental. Vale ressaltar que o desenho do curso foi projetado para a concentração da tutoria na sede da IES, prevendo nos pólos uma tutoria de cunho administrativo e não de conteúdo. A tutoria na sede conta com 21 tutores, em três turnos, tendo horário de atendimento das 8:00h às 20:00h, de segunda a sexta-feira.

O próximo item analisado foi o acesso a bibliotecas, citado por $44,34 \%$ dos estudantes. Com o intuito de melhorar este quadro, o curso vem mantendo contato com a Diretoria da Biblioteca Central da UFSC. Como resultado desse contato, obtiveram-se as seguintes ações: comprou-se mais de 200 exemplares para bibliotecas setoriais, localizadas nos pólos de ensino, para consulta local; qualquer aluno a distância pode solicitar os livros do acervo da biblioteca central, sendo que a mesma arca com os custos de postagem do envio pro aluno, e, após o período de empréstimo, o aluno posta este exemplar de volta à biblioteca; está sendo desenvolvida pela equipe do curso uma página dentro do AVEA com conexão para a página da Biblioteca Central, bem como explicações sobre empréstimos e consultas; e foi solicitada a gravação de aulas explicativas para a consulta dos alunos a banco de dados e bibliotecas virtuais, com convênio com a UFSC.

Quanto à estrutura dos pólos de ensino e o laboratório de informática nos pólos de ensino, mais de $70 \%$ dos entrevistados afirmaram que esses itens não interferem negativamente em seu estudo e aprendizagem.

A interatividade do AVEA também não obteve índices preocupantes, visto que sua implementação ocorreu dois meses antes da realização desta pesquisa e os alunos estão se adaptando a esse novo ambiente.

O último fator analisado foi os meios de comunicação oferecidos pelo curso, no qual poucos respondentes afirmaram dificultar seus estudos $(18,69 \%)$. Ressalta-se que o curso utiliza-se dos seguintes meios de comunicação: telefone, fax, e-mail, chat, fórum e mensagem instantânea. Recentemente foram adquiridas webcams, que serão utilizadas também para a comunicação entre aluno-tutor.

Tabela 04: Categoria Requisitos didático-pedagógicos - fatores dificultadores

\begin{tabular}{|c|c|c|c|c|c|c|c|c|c|c|}
\hline & \multicolumn{2}{|c|}{ Não dificulta } & \multicolumn{2}{|c|}{ Dificulta pouco } & \multicolumn{2}{|c|}{ Dificulta } & \multicolumn{2}{|c|}{ Dificulta muito } & \multicolumn{2}{|l|}{ Total } \\
\hline & $\begin{array}{l}\text { Freq. } \\
\text { Abs. }\end{array}$ & $\begin{array}{l}\text { Freq. } \\
\text { Rel. }\end{array}$ & $\begin{array}{l}\text { Freq. } \\
\text { Abs. }\end{array}$ & $\begin{array}{l}\text { Freq. } \\
\text { Rel. }\end{array}$ & $\begin{array}{l}\text { Freq. } \\
\text { Abs. }\end{array}$ & $\begin{array}{l}\text { Freq. } \\
\text { Rel. }\end{array}$ & $\begin{array}{l}\text { Freq. } \\
\text { Abs. }\end{array}$ & $\begin{array}{l}\text { Freq. } \\
\text { Rel. }\end{array}$ & $\begin{array}{l}\text { Freq. } \\
\text { Abs. }\end{array}$ & $\begin{array}{l}\text { Freq. } \\
\text { Rel. }\end{array}$ \\
\hline Carga horária curricular do curso & 227 & $70,94 \%$ & 77 & $24,06 \%$ & 12 & $3,75 \%$ & 4 & $1,25 \%$ & 320 & $100,00 \%$ \\
\hline $\begin{array}{l}\text { Relação do Currículo com o mercado de } \\
\text { trabalho }\end{array}$ & 258 & $83,50 \%$ & 40 & $12,94 \%$ & 6 & $1,94 \%$ & 5 & $1,62 \%$ & 309 & $100,00 \%$ \\
\hline Critérios de avaliação do aluno & 195 & $61,90 \%$ & 95 & $30,16 \%$ & 21 & $6,67 \%$ & 4 & $1,27 \%$ & 315 & $100,00 \%$ \\
\hline Associação entre a teoria e a prática & 167 & $51,54 \%$ & 118 & $36,42 \%$ & 31 & $9,57 \%$ & 8 & $2,47 \%$ & 324 & $100,00 \%$ \\
\hline Relação entre conteúdos das disciplinas & 243 & $77,64 \%$ & 55 & $17,57 \%$ & 12 & $3,83 \%$ & 3 & $0,96 \%$ & 313 & $100,00 \%$ \\
\hline Encontros presenciais & 198 & $62,66 \%$ & 76 & $24,05 \%$ & 25 & $7,91 \%$ & 17 & $5,38 \%$ & 316 & $100,00 \%$ \\
\hline Grau de dificuldade dos exercícios e provas & 157 & $48,91 \%$ & 136 & $42,37 \%$ & 22 & $6,85 \%$ & 6 & $1,87 \%$ & 321 & $100,00 \%$ \\
\hline Contato entre colegas de cursos & 156 & $48,60 \%$ & 115 & $35,83 \%$ & 39 & $12,15 \%$ & 11 & $3,43 \%$ & 321 & $100,00 \%$ \\
\hline $\begin{array}{l}\text { Reprovação em mais de duas disciplinas no } \\
\text { semestre }\end{array}$ & 187 & $65,16 \%$ & 34 & $11,85 \%$ & 25 & $8,71 \%$ & 41 & $14,29 \%$ & 287 & $100,00 \%$ \\
\hline Prazos de entrega das atividades & 157 & $49,22 \%$ & 122 & $38,24 \%$ & 26 & $8,15 \%$ & 14 & $4,39 \%$ & 319 & $100,00 \%$ \\
\hline Avaliação dos exercícios & 216 & $67,08 \%$ & 79 & $24,53 \%$ & 26 & $8,07 \%$ & 1 & $0,31 \%$ & 322 & $100,00 \%$ \\
\hline Avaliações das provas & 197 & $61,37 \%$ & 92 & $28,66 \%$ & 23 & $7,17 \%$ & 9 & $2,80 \%$ & 321 & $100,00 \%$ \\
\hline Material didático ofereci & 254 & $79,13 \%$ & 56 & $17,45 \%$ & 10 & $3,12 \%$ & 1 & $0,31 \%$ & 321 & $100,00 \%$ \\
\hline $\begin{array}{l}\text { Qualidade do curso de administração a } \\
\text { distância }\end{array}$ & 253 & $80,57 \%$ & 43 & $13,69 \%$ & 9 & $2,87 \%$ & 9 & $2,87 \%$ & 314 & $100,00 \%$ \\
\hline
\end{tabular}


Fonte: dados primários

A última categoria interna às IES a ser analisada foram os requisitos didáticopedagógicos. Primeiramente destaca-se que o indicador que obteve maior percentual quanto a dificultar muito para os alunos, foi a reprovação em mais de duas disciplinas no semestre, com 14,29\% das respostas. Essa ação consta no Plano Pedagógico do curso que prevê que os alunos que reprovarem em mais de duas disciplinas no semestre estão automaticamente desligados do curso.

Outro item, o contato com os colegas do curso, foi citado por 51,4\% dos entrevistados, como limitador ao seu estudo e aprendizagem. Para isso, propõe-se o estímulo a mais grupos de estudos, a encontros entre os alunos e comunidades virtuais, podendo essas ações ficar a cargo dos monitores dos pólos.

Quanto às atividades do curso, dois itens foram citados pelos alunos como dificultador, o prazo de entregas das atividades $(50,78 \%)$ e o grau de dificuldade dos exercícios e provas $(51,09 \%)$. Em relação aos prazos das atividades, tem-se normalmente uma semana para a realização de cada atividade, lembrando-se que uma disciplina de 60 horas tem a duração de um mês. Já as provas presenciais correspondem a $60 \%$ da nota final do aluno em cada disciplina. O grau de dificuldade dos exercícios e provas tem como objetivo manter um grau de qualidade pretendido pela coordenação do curso e do projeto piloto.

A associação entre teoria e prática também foi citado por $48,46 \%$ como podendo dificultar seus estudos. Para isso recomenda-se a utilização de estudos de casos, seminários, indicação de filmes e artigos nos quais os alunos possam observar a teoria aplicada nas organizações e em seu dia a dia.

Também se ressalta o desempenho favorável de dois indicadores, a qualidade do curso de Administração a distância e a relação do currículo com o mercado de trabalho, os quais foram citados por poucos alunos como dificultadores do processo de ensino e aprendizagem.

\section{CONCLUSÕES}

A educação é uma das principais bases para o crescimento econômico e social de um país. A expansão da educação superior no Brasil, devido à sua extensão territorial, é um desafio para os governantes. A educação a distância vem ao encontro deste desafio, podendo minimizar os problemas territoriais e democratizar a educação superior no país.

Em busca de informações para uma das IES participante do projeto piloto da $\mathrm{UAB} / \mathrm{MEC}$, este trabalho objetivou analisar os fatores dificultadores à permanência dos alunos e seus reflexos no processo de evasão no curso de graduação em Administração a distância da Universidade Federal de Santa Catarina.

Para isso, identificaram-se, de acordo com o estado da arte, os fatores dificultadores à permanência dos alunos nos cursos de graduação e na modalidade a distância, chegando-se assim a duas dimensões de análise: categorias externas às IES e categorias internas às IES.

Quanto às categorias externas, obteve-se a seguinte classificação: sócio-políticoeconômico, vocação pessoal, características individuais e conjunturais. Já as categorias internas às IES foram: atitude comportamental, motivos institucionais e requisitos didático-pedagógicos.

Em relação a identificar e analisar os fatores dificultadores do processo de aprendizagem dos alunos do curso pôde-se destacar, quanto às categorias externas às IES, alguns indicadores como: tempo para estudar, carga horária semanal de trabalho, 
adaptação à modalidade a distância, situação econômica financeira e responsabilidade econômica no sustento da família.

Já os indicadores da categoria interna às IES mais presentes foram: contato com o professor, a ausência de tutores nos pólos, acesso a bibliotecas, reprovação em mais de duas disciplinas no semestre, contato com os colegas do curso, prazo de entregas das atividades e grau de dificuldade dos exercícios e provas.

Para que as informações advindas dessas pesquisas sejam utilizadas efetivamente, enfatiza-se a necessidade de uma estrutura adequada para a equipe de gestão do curso. Isso implica em apoio institucional e governamental no caso deste projeto, com o repasse dos recursos necessários.

A expansão da EAD no Brasil deve vir acompanhada de uma política governamental de comprometimento com as IES, ou seja, a garantia de que os recursos necessários sejam repassados de forma suficiente e nos prazos estipulados. Este fato é imperativo, pois não se pode deixar que os profissionais que estão comprometidos e motivados com essa modalidade tenham suas expectativas não atendidas por divergências de qualquer natureza.

Complementa-se que a gestão destes cursos deve estar comprometida com a qualidade. A ampliação quantitativa da educação superior brasileira por meio dessa modalidade precisa vir acompanhada da qualidade do ensino, para gerar assim o desenvolvimento sócio-econômico do país.

\section{REFERÊNCIAS}

ABRAED - Anuário Brasileiro Estatístico de Educação Aberta e a Distância. 3.ed. São Paulo: Instituto Monitor, 2007.

ARETIO, García Lorenzo. La educación a distancia: de la teoría a la práctica. Barcelona: Ariel, 2002.

ARIAS, José Manuel Carrión. Una mirada crítica a la educación a distancia. Revista Iberoamericana de Educación. 2005. Disponível em < http://www.rieoei.org/deloslectores/11Carrion.pdf> Acesso em fev. 2007.

BARBERÀ, Elena (coord). Educación abierta y a distancia. Barcelona: UOC, 2006. BIAZUS, Cleber Augusto. Sistema de fatores que influenciam o aluno a evadir-se dos cursos de graduação na UFSM e na UFSC: um estudo no curso de Ciências Contábeis. Florianópolis, 2004. Tese. (Doutorado em Engenharia de Produção). Universidade Federal de Santa Catarina.

MAIA, Marta de Campos; MEIRELLES, Fernando de Souza. Tecnologias de informação e comunicação e os índices de evasão nos cursos a distância. 2005. Disponível em < http://www.abed.org.br/congresso2005/por/pdf/181tcc3.pdf> Acesso em fev. 2007.

MINISTÉRIO DA EDUCAÇÃO E CULTURA. Referenciais de qualidade para cursos a distância. $2003 . \quad$ Disponível em $<$ http://portal.mec.gov.br/seed/arquivos/pdf/ReferenciaisdeEAD.pdf $>$. Acesso em fev. 2007.

RUMBLE, Greville. A gestão dos sistemas de ensino a distância. Brasília: Universidade de Brasília: Unesco, 2003.

SIMONSON, Michael. In: BARBERÀ, Elena (coord). Educación abierta y a distancia. Barcelona: UOC, 2006.

UNESCO. Aprendizagem aberta e a distância: perspectivas e considerações políticas educacionais. Florianópolis: Imprensa Universitária, UFSC, 1997. 